\title{
ANÁLISE DA SALIVA NAS DESORDENS SISTÊMICAS
}

\section{ANALYSIS OF SALIVA IN SYSTEMIC DISORDERS}

\author{
José Alexandre da Rocha Curvelo* \\ Dennis de Carvalho Ferreira** \\ Elicardo Alves de Souza Gonçalves*** \\ Martinna de Mendonça e Bertolini**** \\ Liana Bastos Freitas Fernandes*****
}

\begin{abstract}
RESUMO
Introdução: A saliva humana possui um amplo grupo de constituintes proteicos e não proteicos que possuem um imenso potencial informativo para a detecção de doenças sistêmicas. De forma geral, as alterações sistêmicas alteram o funcionamento das glândulas salivares de forma direta ou indireta, e essas alterações, ao serem detectadas e mensuradas, podem contribuir para o diagnóstico precoce de doenças. O objetivo deste estudo é revisar a literatura sobre as possíveis aplicações diagnósticas fornecidas pela análise da saliva e de suas alterações perante as desordens sistêmicas. Conclusão: Concluiu-se que a análise do fluido salivar com finalidade diagnóstica se fundamenta na possível correlação entre os constituintes salivares e os parâmetros bioquímicos tradicionais, como do plasma. Dentre as possíveis aplicações diagnósticas da saliva, pode-se destacar a comprovação de desordens hereditárias, a identificação e monitoramento de alterações imunológicas o diagnóstico e acompanhamento de processos infecciosos, além do controle da resposta imunológica e dos níveis hormonais.
\end{abstract}

DESCRITORES: Saliva • Diagnóstico • Síndrome de Imunodeficiência Adquirida.

\section{ABSTRACT}

Introduction: The human saliva has a wide range of constituent protein for maintenance of the oral cavity, which has a huge potential information for the detection of systemic diseases. The systemic changes, in general, deregulate the functioning of the salivary glands in a direct or indirect way, and the changes detected may contribute to early diagnosis of diseases. This study reviewed the literature on the potential diagnostic applications provided through the analysis of saliva and its amendments facing systemic disorders. Conclusion: It was concluded that the analysis of salivary fluid for diagnostic purposes is based on the possible correlation between salivary constituents and traditional biochemical parameters, especially the plasma. Among the possible diagnostic applications of saliva, we can highlight the evidence of hereditary disorders, the identification and monitoring of immunological changes the diagnosis and monitoring of infection and control of immune response and hormone levels.

DESCRIPTORS: Saliva • Diagnosis • Acquired Immunodeficiency Syndrome

\footnotetext{
* Especialista em Estomatologia pela Universidade Federal do Rio de Janeiro - UFRJ; Mestre em Microbiologia pela UFRJ; Doutorando em Microbiologia pela UFRJ (alexandrecurvelo@hotmail.com)

** Especialista em Estomatologia pela UFRJ; Doutorando em Microbiologia pela Universidade Federal do Rio de Janeiro -UFRJ. (denniscf@gmail.com)

*** Físico, Habilitação em Física Médica pela Universidade Federal do Rio de Janeiro -UFRJ (elicardo@gmail.com)

**** Graduada em Odontologia pela FO-UFRJ, Mestranda em Prótese Dentária pela FO/Universidade Estadual do Rio de Janeiro - UERJ, (martinnabertolini@ gmail.com)

***** Especialista em periodontia pela Universidade Federal do Rio de Janeiro - UFRJ; mestre e doutora em periodontia pela Lund University/Suecia- Pesquisadora Instituto de Bioquímica Médica pela Universidade Federal do Rio de Janeiro - UFRJ (liana.fernandes@clinicaeso.com.br)
} 
CURVELO JAR,

FERREIRA DC, GONÇALVES EAS, BERTOLINI MM, FERNANDES LBF.

ANÁLISE DA SALIVA NAS DESORDENS SISTEMMICAS

REVISTA DE ODONTOLOGIA DA UNIVERSIDADE CIDADE DE SÃO PAULO $2010 ; 22(2):$ $163-73$, MAI $A G 0$

\section{N T RO DUÇÃO}

A saliva humana possui um amplo grupo de constituintes proteicos e não proteicos com o propósito de manter a saúde da cavidade oral. Esse arsenal de componentes possui um imenso potencial informativo para a detecção de doenças sistêmicas. Entretanto, esse potencial só poderá ser traduzido em metodologias efetivas a partir do estabelecimento de um padrão referencial dos compostos salivares (Xie et al. ${ }^{1}$ 2005). A partir desse padrão referencial, a interpretação qualitativa e quantitativa dos componentes da saliva poderá não só determinar o diagnóstico, mas também avaliar o melhor tratamento para desordens sistêmicas.

A ideia da utilização da saliva como matriz de análise para métodos de diagnóstico existe há muito tempo Dawes ${ }^{2}$ 1975, e a criação da nova metodologia pode ser pertinente e viável devido à facilidade da coleta desse fluido e a quantidade de informações determinantes em seus constituintes (Dawes² 1975, Streckfus e Bigler ${ }^{3}$ 2002).

Várias aplicações diagnósticas utilizando a saliva como matriz de análise já foram relatadas como possíveis, dentre elas, a comprovação dae desordens hereditárias, a identificação precoce de alterações imunológicas e de processos infecciosos, o controle da resposta imunológica e dos níveis hormonais, a monitoração do uso de medicamentos, a detecção de drogas ilícitas e até mesmo a avaliação do meio ambiente Kaufman e Lamster ${ }^{4}$ 2002, Wong 2006.

As alterações sistêmicas, de modo geral, alteram o funcionamento das glândulas salivares de forma direta ou indireta. E tais alterações, ao serem detectadas e mensuradas na composição final da saliva, podem contribuir para o diagnóstico e detecção precoce dessas doenças Pederson et al. ${ }^{6}$ 2002. Assim, o objetivo deste estudo é revisar a literatura sobre as possíveis aplicações diagnósticas da saliva e de suas alterações perante as desordens sistêmicas.

\section{APLICAÇÕES DIAGNÓSTICAS}

Doenças Hereditárias
Fibrose Cística (FC)

A FC é uma desordem genética onde o gene defeituoso, presente no cromossomo sete, é responsável pela codificação de uma proteína, denominada Regulador de Condução Transmembrana da Fibrose Cística (RCTFC). A FC se caracteriza pelo defeito de transporte de eletrólitos nas células epiteliais que resulta na produção de uma secreção mucoviscosa pelas glândulas exócrinas Kaufman e Lamster ${ }^{4} 2002$. Como existem muitas mutações gênicas associadas a essa doença, a análise do DNA não é normalmente utilizada como ferramenta diagnóstica, e por isso o diagnóstico é estabelecido através de características clínicas e da análise da concentração dos eletrólitos. Devido à alteração na produção convencional de todas as glândulas exócrinas, a composição final da saliva é alterada, e além do fluxo salivar diminuído (Ceder et al. ${ }^{7}$ 1985), pode ser identificado o aumento dos eletrólitos da saliva submandibular, como cálcio, sódio, cloretos, bicarbonato, potássio e fosfatos (Aps et al. ${ }^{8}$ 2002), além da ureia e do ácido úrico (Boat et al. ${ }^{9}$ 1974), o que causa um "turvamento" do fluido salivar Mangos e Donelly ${ }^{10} 1981$. A saliva parotídea não demonstra alterações significativas em sua composição, provavelmente por sua natureza exclusivamente serosa. O aumento dos níveis salivares de prostaglandina E2 e a presença de uma forma alterada de fator de crescimento epitelial (FCE) também já foram relatados (Aubert et al. ${ }^{11} 1990$ ).

Os estudos relacionados à aplicação da saliva na detecção da FC são relativamente antigos, o que faz com que esse fluído não seja utilizado como meio diagnóstico na detecção da doença, apesar de sua potencialidade (Kaufman e Lamster ${ }^{4}$ 2002).

Tem sido sugerido que a alteração na concentração dos eletrólitos na saliva total de pacientes com FC está relacionada com o índice de cárie, geralmente aumentado nesses pacientes. Porém, como o papel específico desses componentes na patogenia da cárie ainda não está bem estabelecido, não podem ser considerados como fatores diagnósticos Aps et al. ${ }^{8} 2002$.

Doença Celíaca (DC)

A DC é uma desordem de origem con- 
gênita do intestino delgado, relacionada à deficiência na absorção do glúten. $\mathrm{O}$ maior componente do glúten é uma proteína denominada gliadina, e pacientes com tal desordem apresentam anticorpos detectáveis contra essa proteína no plasma. A detecção e a mensuração desse anticorpo na saliva podem ser eficientes no diagnóstico e no acompanhamento do paciente celíaco. Estudos sugerem que a mensuração da IgA secretória antigliadina na saliva possui sensibilidade e especificidade suficiente para que esta seja usada como ferramenta diagnóstica válida, antes mesmo da biópsia intestinal (A-Bayaty et al. ${ }^{12}$ 1989, Hakeen et al. ${ }^{13}$ 1992), que é considerada padrão-ouro no diagnóstico de DC. O aumento nas concentrações de proteínas totais, IgG, peroxidase e mieloperoxidase também já foi relatado nesses pacientes (Lenander -Lumikari et al. ${ }^{14}$ 2000).

Deficiência de Hidroxilase 21 (DH21)

A DH21 é uma desordem hormonal que leva a uma forma de hiperplasia adrenal congênita denominada de "não clássica" (Elias e Castro ${ }^{15}$ 2003, Guechot et al. $\left.{ }^{16} 1985\right)$. As características clínicas dessa desordem estão relacionadas às manifestações de hiperandrogenismo, como puberdade precoce, hirsutismo, alopécia, distúrbios menstruais, síndrome metabólica, disfunção psicológica e infertilidade (Yarak et al. ${ }^{17}$ 2005, Killen et al. ${ }^{18}$ 1992). Os níveis salivares do hormônio 17-hidroxiprogesterona (17HPg) se apresentam significativamente elevados na saliva préprandial de tais pacientes, o que sugere que o fluido pode desempenhar um papel diagnóstico confiável na DH21 (Nóbrega et al. ${ }^{19}$ 2004, Guechot et al. ${ }^{16}$ 1985).

\section{Doenças Autoimunológicas}

2.1 - Síndrome de Sjögren (SS)

A SS é definida como uma exocrinopatia autoimunológica de origem desconhecida, com alta incidência entre mulheres a partir da quarta década de vida. Devido à ausência de marcadores específicos, $\mathrm{O}$ diagnóstico da SS por vezes se torna desafiador, e normalmente é estabelecido através de características clínicas da doença e de dados laboratoriais. Alterações de fluxo salivar, pH, capacidade tampão e a presença de grandes quantidades de lactobacilos e de leveduras na saliva já foram propostos como critério para o diagnóstico de SS (Sreebny e Zhu ${ }^{20}$ 1996). Alguns autores, ainda, defendem que apenas a concentração de $\mathrm{Na}+$ acima de 20nmol// na saliva, associada à sialometria estimulada menor que $0.05 \mathrm{ml} / \mathrm{min}$, já são critérios suficientes para o diagnóstico de SS (Kalk et al. ${ }^{21}$ 2002).

Fisiopatologicamente, a SS se caracteriza pela redução na secreção lacrimal e salivar ocasionando cerato-conjuntivite e xerostomia. A associação de alterações autoimunológicas do tecido conectivo como a artrite reumatoide ou o lúpus eritematoso determina a forma secundária da doença. O critério diagnóstico atual para SS é a apresentação hispatológica de um infiltrado linfocítico no parênquima glandular obtido através da biópsia de glândulas salivares menores. A análise bioquímica do plasma pode apresentar hipergamaglobulinemia e elevados níveis de fator reumatoide, anticorpo antinuclear SS-A e SS-B, que não são marcadores específicos para a SS4. A análise bioquímica da saliva apresenta um aumento significativo na concentração de sódio e de cloretos, e também índices elevados de $\lg \mathrm{A}$, IgG e lactoferrina. Elevados níveis lipídicos (Slomiany et al. ${ }^{22}$ 1986) de cistatina C e S (Van der Reijden et al. ${ }^{23}$ 1996), de PGE2, tramboxano B2, receptor de interleucina 2 e calicreina também foram evidenciados em estudos anteriores (Friberg et al. ${ }^{24}$ 1988). Entretanto, não houve comprovação da correlação entre esses dados e o diagnóstico definitivo de SS. Desse modo, a análise sialoquímica não é incluída em nenhum critério diagnóstico reconhecido para a SS atualmente (Soto-Rojas et al. ${ }^{25}$ 2002).

\section{2 - Pênfigo}

O pênfigo é uma condição que descreve um conjunto de quatro doenças vesículo-bolhosas de natureza autoimunológica: o pênfigo vulgar, o pênfigo vegetante, o pênfigo eritematoso e o pênfigo foliáceo. O pênfigo vulgar é a forma mais comum da doença, que acomete pele e mucosas e se caracteriza pela presença de autoanticorpos contra as proteínas desmossômi-
CURVElo Jar,

FERREIRA DC, GonçalVES EAS, BERTOLINI MM, FERNANDES LBF.

ANÁLISE DA SALIVA NAS DESORDENS SISTEMICAS
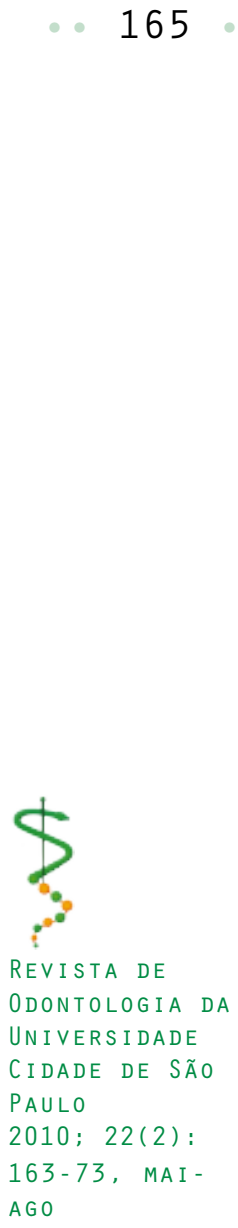
CURVELO JAR,

FERREIRA DC, GONÇALVES EAS, BERTOLINI MM, FERNANDES LBF.

ANÁLISE DA SALIVA NAS DESORDENS SISTEMMICAS

\section{6}

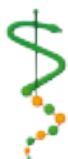

REVISTA DE ODONTOLOGIA DA UNI VERS I DADE CIDADE DE SÃO PAULO $2010 ; 22(2)$ : 163-73, MAI - cas encontrados nas junções epiteliais dos tecidos de revestimento. Os autoanticorpos comprometem a união intercelular do epitélio e, por isso, o diagnóstico é normalmente estabelecido através de exames histopatológicos que evidenciam bolhas intraepiteliais próximas à camada basal do epitélio. A imunofluorescência direta pode confirmar o diagnóstico ao revelar a presença de IgG nos espaços intercelulares do epitélio (Miziara et al. ${ }^{26}$ 2003).

Estudos recentes conseguiram evidenciar os autoanticorpos contra as proteínas desmossômicas na saliva de pacientes com pênfigo. A testagem foi realizada pelo método de ELISA, e demonstrou alta sensibilidade e especificidade, apresentando estreita correlação entre a titulação dos autoanticorpos salivares e os níveis plasmáticos (Andreadis et al. ${ }^{27} 2006$ ).

Considerando-se que a mortalidade do pênfigo vulgar, antes do advento da corticoterapia, ultrapassava $90 \%$, e que o diagnóstico precoce determina a qualidade de vida e o controle da doença, o surgimento de modalidades diagnósticas mais simples, como a utilização da saliva como matriz de análise, é extremamente relevante para o tratamento e o controle dessa desordem (Andreadis et al. ${ }^{27}$ 2006).

\section{3 - Neoplasias Malignas \\ 3.1 - Câncer oral}

De forma geral, os componentes bioquímicos salivares parecem alterar suas concentrações na presença ou iminência de lesões neoplásicas da boca. Segundo alguns autores, essa situação possibilita a criação de um novo painel de concentração de componentes salivares na presença do carcinoma de células escamosas (CCE), o tipo de câncer mais comum da cavidade oral (Shpitzer et al. ${ }^{28} 2007$ ). Este painel consiste em níveis aumentados na concentração de proteínas totais, cálcio, sódio, fósforo e magnésio; de níveis muito aumentados de albumina, lactato, IgG total, fator de crescimento insulínico e metaloproteinases; concentrações diminuídas de amilase e potássio e concentrações muito diminuídas de IgA secretada. A identificação e solidificação desse parâmetro podem estabelecer um método de detecção precoce, simples e eficiente para tais tipos de tumores (Shpitzer et al. ${ }^{28}$ 2007).

Além das possíveis alterações na concentração dos compostos bioquímicos tradicionais, alguns estudos propõem a determinação de algumas estruturas especificas como marcadores dessas situações. Duas proteínas foram recentemente identificadas como supostamente presentes apenas na saliva de pacientes com CCE, a $\alpha$-B-gicoproteina e o fator B do complemento, e podem, dessa forma, representar possíveis marcadores específicos (Ohshiro et al. ${ }^{29}$ 2007).

A proteína supressora de tumor p53 também pode ser apontada como um biomarcador potencial. Essa proteína é produzida por células expostas a danos no DNA, e vários tipos de lesões malignas podem inativá-la, acumulando-a no plasma, o que induz a produção de anticorpos direcionados a ela. Alguns estudos afirmam que esses anticorpos podem ser detectados na saliva de pacientes diagnosticados com CCE (Tavassoli et al. ${ }^{30}$ 1998).

3.2 - Câncer de mama

O aumento significativo na expressão da proteína c-erb-B-2, no fluido salivar de mulheres com neoplasias malignas de mama, tem sido profundamente estudado e sugerido como o biomarcador mais confiável para presença e/ou recorrência dessas lesões (Streckfus e Bigler ${ }^{3}$ 2002). A relação entre os níveis salivares e plasmáticos dessa proteína também foi estabelecida. A sensibilidade e especificidade da c-erb-B-2 na saliva se mostraram superiores aos do PSA (antígeno prostático específico) no plasma, que já é clinicamente utilizado como marcador para a detecção do câncer de próstata, o que endossa sua possível utilização (Bigler et al. ${ }^{31}$ 2002, Sidranky ${ }^{32}$ 2002, Streckfus e Bigler ${ }^{33}$ 2002).

$\mathrm{O}$ fator de crescimento epidérmico (FCE), conhecidamente presente na saliva, também pode ter sua concentração significativamente elevada em mulheres com câncer de mama primário ou em sua recidiva. Isso fez com que estudos anteriores sugerissem que essa proteína fosse indicada como um marcador potencial para malignidades em geral (Streckfus e Bigler ${ }^{3}$ 2002).

Outros marcadores oncológicos como 
o antígeno cancerígeno 15-3 (CA15-3) e 125 (CA125) relacionados ao câncer da mama e ao câncer de ovário respectivamente são detectáveis na saliva e podem funcionar como meio de diagnóstico e de controle de cura para tais lesões. O CA125 possui uma correlação muito semelhante entre seus valores sorológicos e salivares, o que sugere um forte potencial de aplicação diagnóstica para esse antígeno especificamente (Kaufman e Lamster ${ }^{4}$ 2002).

Doenças Infecciosas

4.1 - Infecções bacterianas

O Helicobacter pylori é uma bactéria espiroqueta gram-negativa, conhecida como o patógeno mais comum da mucosa gástrica, infectando mais da metade da população mundial. O H. pylori é reconhecido como o principal agente etiológico da úlcera péptica (Tiwari et al. ${ }^{34}$ 2005), e pode ser evidenciado através da saliva por técnicas de biologia molecular como a PCR para a detecção de fragmentos de seu DNA, ou por ELISA para a detecção de seu anticorpo especifico. Esse tipo de teste pode ter relevância na avaliação do risco de adenocarcinoma gástrico, uma vez que o H. pylori está fortemente associado a esse tumor (Streckfus e Bigler ${ }^{3}$ 2002). A detecção do H. pylori na saliva através de técnicas de PCR demonstrou eficácia em $87 \%$ dos casos estudados, o que torna o fluido salivar um importante meio para diagnosticar a presença desse microrganismo com alto grau de aplicabilidade, considerando-se a caracteristica invasiva dos métodos atualmente utilizados, como a endoscopia (Tiwari et al. ${ }^{34}$ 2005). Entretanto, a análise da saliva por ELISA torna o método menos especifico (70\%), o que pode levar a implicações negativas significantes, se considerada a grande quantidade de infectados (Reilly et al. ${ }^{35}$ 1997).

Estudos anteriores relataram que o aumento na contagem de unidades formadoras de colônias de determinadas bactérias encontradas na saliva, como Capnocytophaga gingivalis, Prevotella melaninogenicaand e Streptococcus mitis, está relacionado com a presença do CCE, e sugerem que tal associação deve ser considerada um critério específico e viável para o diagnóstico de câncer oral (Mager et al. ${ }^{36}$ 2005).

\section{2- Infecções virais}

A detecção de anticorpos específicos é a base para a maioria dos meios de diagnósticos em virologia (Kaufman e Lamster ${ }^{4}$ 2002). O fluido salivar contém tanto anticorpos secretados quanto provenientes do soro, que passaram para a saliva através do fluido crevicular. A identificação e análise desses anticorpos podem funcionar como o diagnóstico de infecções virais agudas, congênitas ou reativações (Mortimer e Parry ${ }^{37}$ 1988).

O potencial diagnóstico da saliva para infecções virais já foi demonstrado para hepatites A, B (Stuart et al. ${ }^{38}$ 1988), e C (El Medany et al. ${ }^{39}$ 1999), através da presença de IgM específica na saliva. O diagnóstico e a testagem de soroconversão para sarampo, cachumba e rubéola também podem ser realizados através da saliva, e apresentam sensibilidade e especificidade satisfatórias e confiáveis para essas infecções (Thieme et al. ${ }^{40}$ 1994). A IgA salivar demonstrou ser o marcador mais sensível para o diagnóstico da infecção por rotavirus em recém-nascidos, quando comparados aos marcadores sorológicos; possivelmente essa situação está relacionada à sobreposição da imunidade materna (Jayashree et al. ${ }^{41}$ 1988).

\subsection{1 - Dengue}

A dengue é uma arbovirose que pode causar complicações severas. Os níveis salivares de IgM e IgG para o vírus da dengue apresentam especificidade de 100\% com sensibilidade de $92 \%$ no diagnóstico da infecção primária e secundária. Além disso, os níveis salivares de IgG são capazes de diferenciar a primo-infecção de infecções secundarias (Cuzzubbo et al. ${ }^{42}$ 1998, Kaufman e Lamster ${ }^{4}$ 2002). A IgM salivar específica (anti-DEN IgM) é considerada um marcador confiável que pode ser utilizado como uma modalidade diagnóstica útil, barata e com grande potencial de penetração para a população de áreas endêmicas (Balmaseda et al. ${ }^{43}$ 2003).

Estudos anteriores detectaram a presença do genoma do vírus da dengue tipo I no fluido salivar e na urina, mas não no plasma, o que reforça a proposição da saliva como método diagnóstico principalmente para crianças e pacientes com a forma hemorrágica da doença, considerando-se
CURVELO JAR,

FERREIRA DC, gonçalves eas, Bertolini MM, FERNANDES LBF.

ANÁLISE DA SALIVA NAS DESORDENS SISTEMMICAS
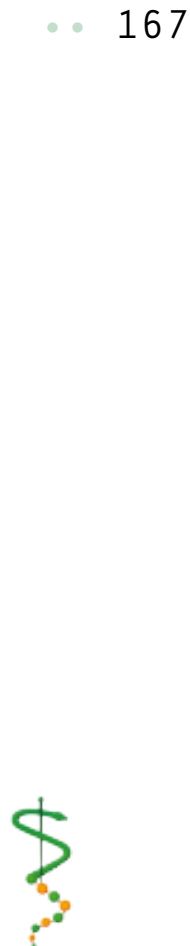

Revista de ODONTOLOGIA DA UNIVERSIDADE CIDADE DE SÃO PAULO 2010; 22(2): $163-73$, MAI $A G 0$ 
CURVELO JAR,

FERREIRA DC, GONÇALVES EAS, BERTOLINI MM, FERNANDES LBF.

ANÁLISE DA SALIVA NAS DESORDENS SISTEMMICAS

\section{8}

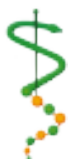

REVISTA DE ODONTOLOGIA DA UNI VERS I DADE CIDADE DE SÃO PAULO $2010 ; 22(2)$ : 163-73, MAI $A G 0$ a simplicidade da coleta (Mizuno et al. ${ }^{44}$ 2007).

\subsection{2 - AIDS}

O método diagnóstico clássico para a infecção por HIV é a detecção do anticorpo viral no plasma por ELISA, que, se reativo, é novamente testado por Western Blotting, para que se evitem resultados falso-positivos (Franco-Paredes et al. ${ }^{45}$ 2006). Esse processo é relativamente longo, levando de 7 a 14 dias, tempo que talvez contribua para a alta taxa de abandono (1/3) dos laudos reativos nos laboratórios. Assim, torna-se necessária a criação de métodos diagnósticos mais rápidos com a finalidade de evitar tal situação (Glick ${ }^{46}$ 2006).

Estudos demonstram que a infecção pelo HIV pode ser diagnosticada pela detecção do anticorpo específico na saliva com a mesma precisão dos exames realizados através da análise plasmática (Streckfus e Bigler ${ }^{3}$ 2002). Dessa forma, o US-FDA (Food and Drug Administration) aprovou a comercialização de quatro novos testes rápidos para a detecção do HIV nos Estados Unidos, sendo um destinado especificamente para a análise da saliva (OraQuick Advance Test $\AA$ - OraSure Technologies; Bethlehem, PA). É um teste qualitativo capaz de fornecer o resultado (reativo ou não reativo) em aproximadamente 20 minutos (Glick ${ }^{46}$ 2006). A análise quantitativa de parâmetros salivares também pode ser possível, tendo-se em vista que os níveis de IgA no fluido salivar tendem a diminuir com a progressão da doença, e, assim, este pode ser um método útil e não invasivo de controle e manejo da infecção (Streckfus e Bigler ${ }^{3}$ 2002).

5- Monitoração dos níveis hormonais

Muitos testes de função endócrina requerem a análise dos níveis hormonais no plasma ou na urina por um grande período de tempo. Os níveis hormonais na saliva representam a forma livre desses hormônios, ou seja, sua forma ativa, enquanto os índices identificados nas medições plasmáticas representam a totalidade dessas estruturas (sua forma livre e ligada à proteína) (Streckfus e Bigler ${ }^{3}$ 2002).

Para que essa proposta metodológica se torne confiável, a mensuração dos níveis hormonais na saliva precisa refletir com exatidão os níveis detectados no soro. Os mecanismos de transporte intra e extraglandulares que possibilitam a presença de drogas no fluido salivar são os mesmos envolvidos no transporte de hormônios. Entretanto, a maioria dos hormônios humanos é lipossolúvel, como os esteroides e, por isso, são transportados para a saliva por difusão passiva através das células acinares. Recentemente, testes para a mensuração do estradiol livre (não ligado) na saliva foram aprovados pelo US-FDA para que sejam usados na expectativa de parto prematuro em gestantes de risco, onde a alta concentração desses hormônios é detectada (Tabak ${ }^{47}$ 2006).

Os hormônios protéicos são muito grandes para que possam atingir a saliva por difusão passiva ou ultrafiltração; então, a presença desse tipo de hormônio no fluido salivar provavelmente ocorre por contaminação da amostra pelo líquido crevicular ou por sangue (Kaufman e Lamster ${ }^{4}$ 2002). A monitoração dos níveis hormonais pela saliva, apesar de extramamente vantajoso, possui ainda limitações analíticas que devem ser consideradas, como, por exemplo, a capacidade de ligação às proteínas plasmáticas, característica da maioria dos hormônios no soro, que faz com que apenas uma fração do hormônio em estudo esteja disponível para se difundir para a saliva. Outro fator importante a ser considerado é o fato de diferentes hormônios poderem se ligar à mesma proteína, e, dessa forma, a alteração nos níveis de um tipo de hormônio pode modificar a concentração da forma livre de outros, tornando as medições pouco confiáveis. Além disso, o ritmo circadiano próprio de vários hormônios, a variação no fluxo salivar e a rápida degradação dos hormônios por enzimas presentes na saliva demonstram variáveis que precisam ser consideradas para a precisão na correlação dos índices hormonais salivares com os do plasma (Laine e Ojanotko ${ }^{48}$ 1999).

\section{I SCUSSÃO}

O fluido salivar pode oferecer uma alternativa ao plasma e à urina, como matriz de análise para o diagnóstico e controle de diversas doenças sistêmicas. A análise da saliva com finalidades diagnósticas se 
fundamenta na possível correlação entre os constituintes salivares e os parâmetros bioquímicos tradicionais, principalmente do plasma (Wong 5 2006).

Bioquimicamente, a maior discrepância entre a saliva e o plasma está relacionada à grande variação dos valores de referência encontrados nos componentes constituintes do fluido salivar. A maioria dos compostos estudados no soro já é bem documentada, e possuem uma posição sólida em relação à sua utilidade e confiabilidade. A variação dos valores de referência desses compostos no plasma se mantém em uma faixa estreita, entretanto o mesmo não acontece na saliva, o que dificulta o desenvolvimento de métodos de análise e a elaboração de valores padronizados desses componentes (Drummer $^{49}$ 2006).

Para que a saliva se torne uma matriz de análise alternativa ao plasma com semelhante grau de confiabilidade, é necessário o estabelecimento de uma correlação confirmada entre as concentrações dos compostos nos dois meios. Vários fatores podem levar à danificação da saliva como amostra de análise, como a contaminação por sangue, que faria com que a quantidade estimada das moléculas presentes na saliva fosse comprometida com a presença de compostos essencialmente plasmáticos (Chiappin et al. ${ }^{50}$ 2007). O ritmo circadiano representa também um fator importante a ser considerado, pois sendo capaz de alterar o fluxo salivar em períodos específicos do dia, o valor das expressões dos compostos salivares poderia ser consequentemente alterado (Dawes $^{2}$ 1975). Estudos já demonstraram que a própria escovação dentária pode alterar a concentração de proteínas na saliva por um período especifico de tempo, provavelmente através da contaminação do fluido por constituintes plasmáticos (Hoek et al. ${ }^{51}$ 2002). Desse modo, o processamento da analise da saliva por múltiplos métodos pode se tornar necessário, pois, apesar de alguns compostos serem detectados em concentrações similares em todos os métodos, cada processo de análise possui especificidade indicativa para determinados tipos de moléculas, sugerindo que um único método pode não avaliar com integridade a total composição do fluido (Ohshiro et al. ${ }^{29}$ 2007).

A análise molecular, com finalidades de diagnóstico ou terapêutico, tende a mudar o paradigma do atendimento clínico atual e possibilitar, além do diagnóstico precoce, o monitoramento da evolução de desordens sistêmicas, além da avaliação do tratamento, por meio de assinaturas protéicas ou biomarcadores que podem ser detectados em diferentes fases da doença ou em resposta ao tratamento (Petricoin et al. ${ }^{52}$ 2002). Para que isso se torne realidade, a criação de uma plataforma de referência confiável dos componentes salivares e de suas concentrações é de essencial importância (Wulfkuhle et al. ${ }^{53}$ 2003).

Parece uma questão de tempo para a utilização da análise salivar como um método diagnóstico em larga escala. Isso tornará a medicina molecular mais acessível, mudando o paradigma do atendimento clínico atual e dos critérios estabelecidos de diagnóstico, prognóstico e de tratamento (Petricoin et al. ${ }^{52}$ 2002, Wulfkuhle et al. ${ }^{53}$ 2003). Os cirurgiões-dentistas provavelmente se tornarão mais próximos e envolvidos nesse processo de diagnóstico e monitoramento de desordens sistêmicas, considerando seu campo de trabalho e sua acessibilidade e familiaridade com essa nova e promissora matriz de análise (Hodgson et al. ${ }^{44}$ 2006).

\section{CONCLUSÕES}

As doenças sistêmicas alteram funcionamento das glândulas salivares e comprometem a composição final da saliva. A análise dessas alterações pode servir como critério diagnóstico para essas desordens.

A análise salivar com finalidade diagnóstica se fundamenta na possível correlação entre os constituintes salivares e os parâmetros bioquímicos tradicionais, principalmente do plasma.

Dentre as possíveis aplicações diagnósticas da saliva, pode-se destacar a comprovação de desordens hereditárias, a identificação e o monitoramento de alterações imunológicas, o diagnóstico de processos infecciosos e o controle e monitoramento dos níveis hormonais.

Os diagnósticos das doenças autoimunológicas são, por vezes, desafiadores,
CURVElo Jar, FERREIRA DC, GonçalVES EAS, BERTOLINI MM, FERNANDES LBF.

ANÁLISE DA SALIVA NAS DESORDENS SISTEMICAS

$\therefore 169$

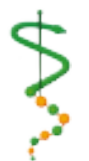

REVISTA DE ODONTOLOGIA DA UN I VERS I DADE CidAde de São PAULO 2010; 22(2): 163-73, MAI A G 0 
CURVELO JAR,

FERREIRA DC, GONÇALVES EAS, BERTOLINI MM, FERNANDES LBF.

ANÁLISE DA SALIVA NAS DESORDENS SISTÊMICAS devido à sua característica inespecífica e silenciosa e, dessa forma, a criação de métodos analíticos mais simples pode ser de grande importância para o diagnóstico precoce e controle de tais enfermidades.

Uma ampla variedade de doenças infecciosas pode ser diagnosticada e monitorada a partir da detecção de anticorpos específicos na saliva; entretanto, outras técnicas para a detecção de partes de mi- crorganismos, como as técnicas atuais de biologia molecular, podem ser úteis para essa finalidade.

A mensuração dos níveis hormonais no fluido salivar pode diagnosticar precocemente diversas alterações hereditárias, como a deficiência da hidroxilase (Kalk et al. ${ }^{21}$ 2002), e também determinar o risco de parto prematuro em gestantes de alto risco.

\section{REFERÊNCIAS}

1. Xie H, Rhodus NL, Griffin RJ, Carlis JV, Griffin TJ. A catalogue of human saliva proteins identified by free flow Eelectrophoresis-based peptide separation and tandem mass spectrometry. Mol Cell Proteomics 2005 Nov; 4(11):1826-30

2. Dawes C. Circadian rhythms in the flow rate and composition of unstimulated and stimulated human submandibular saliva. J Physiol. 1975 Jan; 244(2): 535-48.

3. Streckfus CF, Bigler LR. Saliva as a diagnostic fluid. Oral Diseases 2002 Mar; 8(2): 69-76

4. Kaufman E, Lamster IB. The diagnostic applications of saliva- a review. Crit Rev Oral Biol Med 2002; 13(2): 197-212

5. Wong DT. Salivary diagnostics powered by nanotechnologies, proteomics and genomics. J Am Dent Assoc 2006 Mar; 137(3): 313-21.

6. Pedersen AM, Bardow A, Jensen SB et al. Saliva and gastrointestinal functions of taste, mastication, swallowing and digestion, Oral Diseases 2002 May; 8(3): 11729

7. Ceder O, van Dijken J, Ericson T, Kollberg H. Ribonuclease in different types of saliva from cystic fibrosis patients. Acta Paediatr Scand.1985 Jan; 74(1): 102-6

8. Aps JK, Delanghe J, Martens LC. Salivary electrolyte concentrations are associated with cystic fibrosis transmembrane regulator genotypes. Clin Chem Lab Med. 2002 Apr; 40(4): 345-50

9. Boat TF, Wiesman UN, Pallavicinni JC. Purification and properties of the calciumprecipitable protein in submaxillary saliva of normal and cystic fibrosis subjects. Pediatr Res.1974 May; 8(5): 531-9

10. Mangos JA, Donnelly WH. Isolated Parotid Acinar Cells from Patients with Cystic Fibrosis. Morphology and Composition. J Dent Res1981 Jan; 60(1): 19-25

11. Aubert B, Cochet C, Souvignet C et al. Saliva from cystic fibrosis patients contains an unusual form of epidermal growth factor. Biochem Biophys Res Commun. 1990 Aug 16; 170(3): 1144-50.

12. Al-Bayaty HF, Aldred MJ, Walker DM, et al. Salivary and serum antibodies to gliadin in the diagnosis of celiac disease. Journal of Oral Pathology \& Medicine 1989 Dec; 18(10): 578-81.

REVISTA DE

13. Hakeem V, Fifield R, al-Bayaty HF et al. Salivary IgA antigliadin antibody as a marker for coeliac disease. Arch Dis Child. 1992 Jun;67(6):724-7

14. Lenander-Lumikari M, Ihalin R, Lahteenoja $\mathrm{H}$. Changes in whole saliva in patients with celiac disease. Archives of Oral Biology 2000 May; 45(5): 347-54 
15. Elias LLK, Castro M. Diagnóstico da forma não clássica da deficiência de 21-Hidroxilase. Redefinição de critérios após estudos moleculares. Arq Bras Endocrinol Metab 2003 out; 47(5): 511-3

16. Guechot J, Fiet J, Gourmelen M, et al. Radioimmunoassay of salivary I7 alpha-hydroxyprogesterone. Values obtained in healthy subjects and in patients treated for congenital hyperplasia of the adrenal glands. Ann Biol Clin 1985; 43(4): 333-7

17. Yarak S, Bagatin E, Hassun KM, Parada MOAB, Talarico Filho S. Hiperandrogenismo e pele: síndrome do ovário policístico è resistência periférica à insulina. Ann Bras Dermatol. 2005 jul-ago; 80(4): 395-410

18. Killeen AA, Hanson NQ, Eklund R, Cairl CJ, Eckfeldt JH. Prevalence of nonclassical congenital adrenal hyperplasia among women self-referred for electrolytic treatment of hirsutism. Am J Med Genet 1992 Jan; 42(2): 197-200

19. Nóbrega LHC, Lima JG, Nóbrega MLC, BritoALS, Mendonça RP. Hiperplasia Adrenal Congênita: Dosagem da 17-Hidroxiprogesterona Basal para Seleção e Casos para Realização do Teste de Estímulo com ACTH Sintético. RBGO 2004: 26 (4):295-8

20. Sreebny LM, Zhu WX. The use of whole saliva in the differential diagnosis of Sjögren's syndrome. Adv Dent Res. 1996; 10(1): 17-24.

21. Kalk WWI, Vissink A, Stegenga B, Bootsma H, Amerongen AVN \& Kallenberg CGM. Sialometry and sialochemistry: a non-invasive approach for diagnosing Sjögren's syndrome. Ann Rheum Dis 2002 Feb; 61(2): 137-44

22. Slomiany BL, Kosmala M, Nadziejko C et al. Lipid composition and viscosity of parotid saliva in Sjögren syndrome in man. Arch Oral Biol 1986; 31(10): 699-702

23. Van der Reijden WA, van der Kwaak JS, Veerman EC et al. Analysis of the concentration and output of whole salivary constituents in patients with Sjögren's syndrome. Eur J Oral Sci. 1996; 104(4):335-40

24. Friberg B, Jonsson R, Linde A. Salivary kallikrein in Sjögren's syndrome. Clin Exp Rheumatol. 1988 Apr-Jun; 6(2): 135-8

25. Soto-Rojas AE, Kraus A. The Oral Side of Sjögren Syndrome. Diagnosis and Treatment:A Review. Archives of Medical Research 2002 Mar-Apr; 33(2) 95-106

26. Miziara ID, Ximenes-Filho JA, Ribeiro FC, Brandão AL. Acometimento Oral do Pênfigo Vulgar.Rev Bras Otorrinolaringol. 2003;69(3): 327:31

27. Andreadis D, Lorenzini G, Drakoulakos D, et al. Detection of pemphigus desmoglein and desmoglein 3 autoantibodies and pemphigoid BP180 autoantibodies in saliva and comparison with serum valuẹ. Eur J Oral Sci 2006 Oct; 114(5): 374-80.

28. Shpitzer T, Bahar G, Freinmesser R, Nagler RM. A comprehensive salivary analysis for oral cancer diagnosis. J Cancer Res Clin Oncol 2007 Sep; 133(9): 613-7

29. Ohshiro K, Rosenthal D; Koomen JM et al. Pre-analytic saliva processing affect proteomic results and biomarker screening of head and neck squamous carcinoma. Int J Oncol 2007 Mar; 30(3): 743-9.

30. Tavassoli M, Brunel N, Maher R, Johnson NW, Soussi T . P53 antibodies in the saliva of patients with squamous cell carcinoma of the oral cavity. Int / Cancer 1998 Oct; 78(3): 390-1.

31. Bigler RL, Streckfus CF, Copeland L et al. The potential use of saliva to detect recurrence of disease in women with breast carcinoma. J Oral Pathol Med 2002 Aug; 31(7): 421-3.
CURVELO JAR, FERREIRA DC, GONÇALVES EAS, BERTOLINI MM, FERNANDES LBF

ANÁLISE DA SALIVA NAS DESORDENS SISTEMICAS

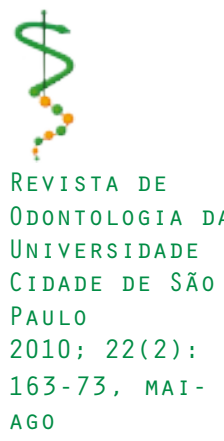


CURVELO JAR,

FERREIRA DC, GONÇALVES EAS, BERTOLINI MM, FERNANDES LBF.

ANÁLISE DA SALIVA NAS DESORDENS SISTEMMICAS

REVISTA DE ODONTOLOGIA DA UNIVERSIDADE CIDAdE DE SÃO PAULO 2010; 22(2): $163-73$, MAI -
32. Sidransky D. Emerging molecular markèrs of cancer. Nature Reviews Cancer 2002 mar; 2(3): 210-19

33. Streckfus C, Bigler L. The use of soluble, salivary c-erbB-2 for the detection and post-operative follow-up of breast cancer in women: the results of a five-year translational research study. Adv Dent Res 2005 Jun;18(1): 17-24

34. Tiwari SK, Khan AA, Ahmed KS, et al. Rapid diagnosis of Helicobacter pylori infection in dyspeptic patients using salivary secretion: a non-invasive approach. Singapore Med J 2005 May; 46(5) : 224-8

35. Reilly TG, Poxon V, Sanders DSA, Elliott TSJ, Walt RP. Comparison of serum, salivary, and rapid whole blood diagnostic tests for Helicobacter pylori and their validation against endoscopy based tests. Gut:1997 Apr; 40(4): 454-8.

36. Mager DL, Haffajee1 AD,Devlin PM, Norris CM, Posner MR, Goodson JM. The salivary microbiota as a diagnostic indicator of oral cancer: A descriptive, non randomized study of cancer-free and oral squamous cell carcinoma subjects. Journal of Translational Medicine 2005 Jul 7; 3:27:

37. Mortimer PP, Parry JV. The use of saliva for viral diagnosis and screening. Epidemiol Infect. 1988 Oct; 101(2): 197-201

38. Stuart JM, Majeed FA, Cartwright KA et al. Salivary antibody testing in a school outbreak of hepatitis A. Epidemiol Infect. 1992 Aug;109(1): 161-6.

39. El Medany OM, El Din Abdel KS, Abu Shady EA et al. Chronic liver disease and hepatitis $C$ virus in Egyptian patients. Hepătogastroenterology. 1999 May-Jun; 46(27): 1895-903

40. Thieme T, Piacentini S, Davidson S et al: Determination of measles, mumps, and rubella immunization status using oral fluid samples. JAMA. 1994 Jul; 272(3): 219-21

41. Jayashree S, Bhan MK, Kumar R, Raj P, Glass R, Bhandari N. Serum and salivary antibodies as indicators of rotavirus infection in neonates J Infect Dis. 1988 Nov; 158(5):1117-20.

42. Cuzzubbo AJ, Vaughn DW, Nisalak A, Suntayakorn S, Aaskov J, Devine PL. Detection of specific antibodies in saliva during dengue Infection. J Clin Microbiol 1998 Dec; 36(12): 3737-9

43. Balmaseda A, Guzman MG, Hammond S. Diagnosis of dengue virus infection by detection of specific immunoglobulin $\mathrm{M}(\operatorname{IgM})$ and $\lg \mathrm{A}$ antibodies in serum and saliva. Clin Diagn Lab Immunol. 2003 Mar; 10(2): 317-22

44. Mizuno Y, Kotaki A, Harada F, Tajima S, Kurane I, Takasaki T. Confirmation of dengue virus infection by detection of dengue virus type 1 genome in urine and saliva but not in plasma.Trans R Soc Trop Med Hyg. 2007 Jul;101(7):738-9.

45. Franco-Paredes C, Tellez I, del Rio C. Rapid HIV testing: a review of the literature and implications for the clinician. Curr HIV/AIDS Rep.2006 Nov; 3(4): 169-75.

46. Glick M. Rapid HIV testing in the dental setting. J Am Dent Assoc 2005 Sep; 136(9): 1206-8.

47. Tabak LA. A revolution in biomedical assessment: the development of salivary diagnostics. J Dent Educ 2001 Dec; 65(12): 1335-9

48. Laine MA, Ojanotko AO. Progesterone metabolism in human saliva in vitro. J Steroid Biochem Mol Biol. 1999 Jul-Ago; 70(1-3): 109-13

49. Drummer OH. Drug testing in oral fluid. Clin Biochem Rev 2006 Aug; 27(3): 14759 
50. Chiappin S, Antonelli G, Gatti R, De Palo EF. Saliva specimen: a new laboratory tool for diagnostic and basic investigation. Clinica Chimica Acta 2007 Aug; 383(1-2): 3040 .

51. Hoek GH, Brand HS, Veerman ECl, Nieuw Amerongen AV. Toothbrushing affects the protein composition of whole saliva. Eur J Oral Sci 2002; 110: 480-481

52. Petricoin EF, Zoon KC, Kohn EC, J. Barrett C, Liotta LA. Clinical proteomics: translating benchside promise into bedside reality. Nature Rev Drug Discov 2002 Sep; 1(9): 683-95.

53. Wulfkuhle JD, Liotta LA, Petricoin EF, Proteomica applications for the early detection of cancer. Nature Reviews Cancer 2003 Apr:3(4): 267-75.

54. Hodgson TA, Naidoo S, Chidzonga M, Ramos-Gomes F, Shiboski C. Identification of oral health care needs in children and adults, management of oral diseases. Adv Dent Res 2006 Apr; 19(1): 106-17.

Recebido em: 12/08/2009

Aceito em: 01/10/2009
CURVELO JAR,

FERREIRA DC,

gonçalves eas,

BERTOLINI MM,

FERNANDES LBF.

ANÁlISE DA

SALIVA NAS

DESORDENS

SISTEMICAS

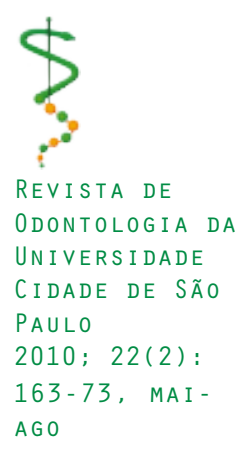

